\title{
Effects of Feeding Metabolite Combinations from Lactobacillus Plantarum on Plasma and Breast Meat Lipids in Broiler Chickens
}

-Author(s)
Loh TCI,V
Thanh NT'
Foo HL ${ }^{\prime \prime I V}$
Hair-Bejo M"I
। Department of Animal Science, Faculty of
Agriculture
" Department of Bioprocess Technology,
Faculty of Biotechnology and Biomolecular
Sciences
III Department of Veterinary Pathology,
Faculty of Veterinary Medicine
Iv Institute of Bioscience
$\vee$ Institute Tropical Agriculture, Universiti
Putra Malaysia, 43400 UPM Serdang,
Selangor, Malaysia

\section{Mail Adress}

Corresponding author e-mail address

Prof. Dr. Loh Teck Chwen

Department of Animal Science

Faculty of Agriculture

Universiti Putra Malaysia

43400, Serdang, Selangor, Malaysia.

Tel: 00-603-89466899

Fax: 00-603-89432954

Email: tcloh@upm.edu.my

\section{- Keywords}

Metabolite combinations, Lactobacillus plantarum, Cholesterol, Very low density lipoprotein, Chicken

\section{METABOLITES ON BROILER PERFORMANCE}

\section{ABSTRACT}

The effects of feeding different doses of metabolite combination of L. plantarum RS5, RI11, RG14 and RG11 strains (Com3456) on cholesterol reduction in plasma and breast meat in broiler chickens and the possible mechanism was studied. A total of 504 male Ross broilers were grouped into 7 treatments and offered with different diets: (i) standard corn-soybean based diet (-ve control); (ii) standard cornsoybean based diet + neomycin and oxytetracycline (+ve control); (iii) standard corn-soybean based diet $+0.1 \%$ metabolite combination of $L$. plantarum RS5, RI11, RG14 and RG11 strains (Com3456); (iv) standard corn-soybean based diet $+0.2 \%$ of Com3456; (v) standard cornsoybean based diet $+0.3 \%$ of Com3456 (vi) standard corn-soybean based diet $+0.4 \%$ of Com3456 and (vii) standard corn-soybean based diet $+0.5 \%$ of Com3456. The metabolite combinations supplemented in the diet of broilers reduced protein, cholesterol esters concentration in very low-density lipoprotein particles. The present of organic acids and proteinaceous compound in the metabolite combinations as found in previous study also increased lactic acid bacteria count in small intestine digesta and improved bile salts deconjugation ability of lactic acid bacteria.

\section{INTRODUCTION}

Metabolites produced by lactic acid bacteria are known for their antibacterial substances, such as organic acids and proteinaceous compounds (Thu et al., 2011a), and broader application in food industries. Recently, these metabolites have attracted attention to be applied in animal feed as growth promoter and potentially used as substitution of in-feed antibiotics (Thanh et al., 2009; Loh et al., 2010; Thu et al., 2010; Thu et al., 2011b, Choe et al., 2012). It has been shown that there is a reduction of plasma cholesterol concentration in rats supplemented with the metabolite (Foo et al., 2003a; Loh et al., 2008). However, the effect of feeding metabolites to broiler chickens on blood lipids and the mechanisms involved are still unclear. Nevertheless, it is believed very low-density lipoproteins (VLDL) play important roles in regulating the cholesterol concentration in the body of broiler chickens. VLDL is known to transport the lipids synthesized in the liver to extrahepatic tissues, such as adipose tissue, muscle, heart, etc. (Devlin, 2002).

Another possible mechanism involved in cholesterol regulation is bile salt deconjugation. Bile is composed of major constituents include bile acids, cholesterol, phospholipids (PL), and the pigment biliverdin (Begley et al., 2006). It involves in emulsifying and solubilizing fats to micelles in vivo. Bile salts are synthesized from cholesterol (Chiang, 
2004). The probability of deconjugated or free bile acids to be excreted from the body is higher than that of conjugated ones (Schiff et al., 1972), mainly due to its lower solubility compared with conjugated bile salts (Center, 1993). Therefore, an increase in bile acid deconjugation in the intestines would continuously drain the cholesterol pool as more bile acids are synthesized for cholesterol compensation. Several studies have reported bile salt hydrolase activity in strains of lactic acid bacteria (LAB) in decongugating bile salts, including L. acidophilus (Walker \& Gilliland, 1993). The bile salt hydrolase enzyme deconjugates bile salts by releasing the glycine and/or taurine moiety from the side chain of the steroid core (Chikai et al., 1987).

Other studies reported the cholesterol-reducing effects of metabolites from Lactobacillus in rats (Foo et al., 2003a, b; Loh et al., 2003) and in humans (Anderson \& Gilliland, 1999). Many studies have been conducted to study the consequences of cholesterol levels due to feeding of $L A B$, but none of the studies utilized the metabolites produced by $L A B$ to study the VLDL lipid profiles and their effects on the LAB in bile salt deconjugation. Therefore, the objectives of present experiments were to determine the effects of feeding metabolite combinations on VLDL lipid profiles and deconjugation ability of $L A B$ isolated from the digesta of small intestine in broiler chickens.

\section{MATERIALS AND METHODS}

\section{Birds and Experimental Design}

A total of 504 male Ross broilers from a local company were reared from day 1 to 42 days of age in a deep litter broiler house. Each pen housed 12 chicks and was randomly allocated to the open house with wood-shaving litter. Upon arrival, birds were vaccinated against IB and ND (IB-ND Fort Dodge, USA) by intraocular route. The vaccine (UPM93, MyVac, Malaysia) against IBD was applied on day 14 of the rearing period. After vaccination, birds were wing banded for monitoring of individual weight. Water and feed were provided ad libitum.

The starter and finisher diets were offered to the birds from $0-21$ and $22-42$ days of age, respectively. The dietary treatments consisted of: (i) corn-soybean basal diet without antibiotic (-ve control); (ii) basal diet with 100ppm (w/W) of neomycin and oxytetracycline (+ve control); (iii) basal diet supplemented with $0.1 \%$ of metabolite combination (Com3456) of 4 strains of L. plantarum RS5 (Com3), RI11 (Com4), RG14 (Com5) and RG11 (Com3456); (iv) basal diet supplemented with $0.2 \%$ metabolite combinations of Com3456; (v) basal diet supplemented with $0.3 \%$ metabolite combinations of Com3456; (vi) basal diet supplemented with $0.4 \%$ metabolite combinations of Com 3456 and (vii) basal diet supplemented with $0.5 \%$ metabolite combination of Com3456.

The metabolites without bacterial cells were produced as described by Thanh et al. (2008). The population of $L$. plantarum used to produce respective metabolite was: Com3, $5.16 \times 10^{8} \mathrm{cfu}$; Com4, $5.90 \times$ $10^{8} \mathrm{cfu}$; Com5, $6.26 \times 10^{8} \mathrm{cfu}$ and Com6, 5.25 × $10^{8} \mathrm{cfu}$. The metabolites were harvested by separating cell-free supernatant (CFS) by centrifugation at 12,000 rpm for $15 \mathrm{~min}$ and then stored at $4^{\circ} \mathrm{C}$. The combinations were mixed with equal volumes of each strain. Com3456 contained bacteriocins (inhibitory activity of $1600 \mathrm{AU} /$ $\mathrm{mL}$ ), lactic acid (concentrations of Com3, $3.47 \mathrm{~g} / \mathrm{L}$; Com4, $5.03 \mathrm{~g} / \mathrm{L}$; Com5, $4.71 \mathrm{~g} / \mathrm{L}$ and Com6, $4.77 \mathrm{~g} / \mathrm{L})$ and acetic acid (concentrations of Com3, $2.02 \mathrm{~g} / \mathrm{L}$; Com4, $1.29 \mathrm{~g} / \mathrm{L}, \mathrm{Com} 5,2.12 \mathrm{~g} / \mathrm{L}$ and Com6, $1.58 \mathrm{~g} / \mathrm{L}$ ). The diets were formulated to meet the requirements of all nutrients for broilers. The percentage composition of starter and finisher diets are presented in Tables 1 and 2 , respectively.

\section{Sample Collection}

Digesta samples from all the segments of small intestine were collected from 12 broiler chickens in each treatment. Birds were fed diets supplemented with different levels of metabolite combinations of 4 strains of L. plantarum. Broiler chickens were slaughtered and blood samples were collected in Vacutainer ${ }^{\circledR}$ tubes containing EDTA as an anticoagulant at a final concentration of $1 \mathrm{mg} / \mathrm{mL}$ of blood mixture. The tubes with samples were mixed well by inverting them gently. Blood samples were then pooled in clean glass test tubes and centrifuged at 1,500 x g for $30 \mathrm{~min}$ at $4^{\circ} \mathrm{C}$. Plasma samples were transferred into clean test tubes using Pasteur pipette equipped with a rubber bulb. Plasma samples were then kept at $-20^{\circ} \mathrm{C}$ until further VLDL separation. Breast muscle was collected from each bird after slaughter and kept at $-20^{\circ} \mathrm{C}$ for determination of cholesterol concentration.

\section{Very Low-Density Lipoprotein Preparation}

VLDL was isolated from the plasma by ultracentrifugal floatation as described by Wright et al. (1995). The analysis of VLDL lipids was conducted as described by Tan et al. (2005). Protein (Sigma Chemical Company Ltd., Poole, Dorset; procedure no. P5656), triacylglycerol (TG) (Wako, Japan), total cholesterol (TC) (Wako, Japan), free cholesterol (FC) (Wako, Japan) and phospholipid (PL) (Wako, Japan) concentrations 
Table 1 - Percentage composition of starter diet

\begin{tabular}{|c|c|c|c|c|c|c|c|}
\hline \multirow[b]{2}{*}{ Ingredients } & \multicolumn{7}{|c|}{ Dietary treatments ${ }^{1}$} \\
\hline & -ve control & +ve control & $\begin{array}{c}0.1 \% \\
\text { Com3456 }\end{array}$ & $\begin{array}{c}0.2 \% \\
\text { Com3456 }\end{array}$ & $\begin{array}{c}0.3 \% \\
\text { Com3456 }\end{array}$ & $\begin{array}{c}0.4 \% \\
\text { Com3456 }\end{array}$ & $\begin{array}{c}0.5 \% \\
\text { Com3456 }\end{array}$ \\
\hline Corn & 50.600 & 50.600 & 50.600 & 50.600 & 50.600 & 50.600 & 50.600 \\
\hline Soybean & 29.382 & 29.382 & 29.382 & 29.382 & 29.382 & 29.382 & 29.382 \\
\hline Wheat Pollard & 6.072 & 6.062 & 5.972 & 5.872 & 5.772 & 5.672 & 5.572 \\
\hline Crude palm oil & 3.600 & 3.600 & 3.600 & 3.600 & 3.600 & 3.600 & 3.600 \\
\hline Fish Meal 55\% & 7.600 & 7.600 & 7.600 & 7.600 & 7.600 & 7.600 & 7.600 \\
\hline L-Lysine & 0.250 & 0.250 & 0.250 & 0.250 & 0.250 & 0.250 & 0.250 \\
\hline DL-Methionine & 0.200 & 0.200 & 0.200 & 0.200 & 0.200 & 0.200 & 0.200 \\
\hline Monodicalcium-phosphate 21 & 1.000 & 1.000 & 1.000 & 1.000 & 1.000 & 1.000 & 1.000 \\
\hline Calcium carbonate & 0.680 & 0.680 & 0.680 & 0.680 & 0.680 & 0.680 & 0.680 \\
\hline Choline chloride & 0.060 & 0.060 & 0.060 & 0.060 & 0.060 & 0.060 & 0.060 \\
\hline Salt & 0.250 & 0.250 & 0.250 & 0.250 & 0.250 & 0.250 & 0.250 \\
\hline Mineral Mix² & 0.100 & 0.100 & 0.100 & 0.100 & 0.100 & 0.100 & 0.100 \\
\hline Vitamin Mix $^{3}$ & 0.060 & 0.060 & 0.060 & 0.060 & 0.060 & 0.060 & 0.060 \\
\hline Antioxidant & 0.010 & 0.010 & 0.010 & 0.010 & 0.010 & 0.010 & 0.010 \\
\hline Alumino silicates & 0.135 & 0.135 & 0.135 & 0.135 & 0.135 & 0.135 & 0.135 \\
\hline Antibiotic $^{4}$ & & 0.010 & & & & & \\
\hline Metabolite powder & & & 0.100 & 0.200 & 0.300 & 0.400 & 0.500 \\
\hline Total & 100 & 100 & 100 & 100 & 100 & 100 & 100 \\
\hline \multicolumn{8}{|l|}{ Calculated analysis: } \\
\hline Crude protein, \% & 22.50 & 22.48 & 22.48 & 22.47 & 22.45 & 22.44 & 22.50 \\
\hline $\mathrm{ME}, \mathrm{kcal} / \mathrm{kg}$ & 2919.90 & 2918.68 & 2918.68 & 2917.48 & 2916.28 & 2915.08 & 2919.90 \\
\hline
\end{tabular}

${ }^{1}$ Diets supplemented with different dosages $(0.1-0.5 \%$, w/w) of metabolite powder of Com3456 (a combination of 4 strains RS5, RI11 RG11 and RG14).

2 Provided per kg diet: Fe 100 mg; Mn 110 mg; Cu 20 mg; Zn 100 mg; I 2 mg; Se 0.2 mg; Co 0.6 mg.

${ }^{3}$ Provided per kg diet: Vitamin A 6,667 IU; vitamin D 1,000 IU; vitamin E 23 IU; vitamin K3 1.33 mg; cobalamin 0.03 mg; Thiamin 0.83 mg; riboflavin 2 mg; folic acid 0.33mg; biotin $0.03 \mathrm{mg}$; pantothenic acid $3.75 \mathrm{mg}$; niacin $23.3 \mathrm{mg}$; pyridoxine $1.33 \mathrm{mg}$.

${ }^{4}$ a combination of oxytetracyclin and neomycin at the concentration of $100 \mathrm{ppm}(\mathrm{w} / \mathrm{w})$.

of VLDL were determined. Cholesteryl ester (CE) was calculated by deduction of FC from TC. The ratios of core lipids (TG/CE), surface lipids (PL/FC) and between surface and core lipids $[(\mathrm{PL}+\mathrm{FC}) /(\mathrm{TG}+\mathrm{CE})]$ were calculated as described by Fungwe et al. (1992) and Loh et al. (2002). The ratios illustrate the proportional relationship between VLDL components and relative VLDL particle size.

\section{Breast Meat Cholesterol Determination}

The analysis was based on the method described by de Almeida et al. (2006). One gram of sample was weighed in a methylation tube. Ten $\mathrm{mL}$ of $2.14 \mathrm{M}$ ethanolic potassium hydroxide solution (Merck, KgaA, Darmstadt) was added. The mixture was homogenized thoroughly before capping and sealing. The mixture was warmed in water bath at $70^{\circ} \mathrm{C}$ for one hour with occasional shaking, and then cooled at room temperature. After cooling to room temperature, the mixture was transferred to a fresh glass centrifuge tube. Ten $\mathrm{mL}$ of petroleum ether, $5 \mathrm{~mL}$ of saturated $\mathrm{NaCl}$ solution and $5 \mathrm{~mL}$ of distilled water were added to the glass-centrifuged tubes, vortexed for $1 \mathrm{~min}$ before centrifugation at 3,000 rpm for $15 \mathrm{~min}$. The upper layer was transferred into a second test tube and re-extracted twice with $10 \mathrm{~mL}$ of petroleum ether (BDH Laboratories, Poole, U.K.), re-centrifuged and the upper petroleum phase was transferred to capped methylation tubes and dried under nitrogen gas until only $1 \mathrm{~mL}$ of the original volume was left. The cholesterol sample was transferred to a $4 \mathrm{~mL}$ screw- 
Table 2 - Percentage composition of finisher diet

\begin{tabular}{|c|c|c|c|c|c|c|c|}
\hline \multirow[b]{2}{*}{ Ingredients } & \multicolumn{7}{|c|}{ Dietary treatments ${ }^{1}$} \\
\hline & -ve control & +ve control & $\begin{array}{c}0.1 \% \\
\text { Com3456 } \\
\end{array}$ & $\begin{array}{c}0.2 \% \\
\text { Com3456 } \\
\end{array}$ & $\begin{array}{c}0.3 \% \\
\text { Com3456 } \\
\end{array}$ & $\begin{array}{c}0.4 \% \\
\text { Com3456 } \\
\end{array}$ & $\begin{array}{c}0.5 \% \\
\text { Com3456 } \\
\end{array}$ \\
\hline Corn & 54.900 & 54.900 & 54.900 & 54.900 & 54.900 & 54.900 & 54.900 \\
\hline Soybean & 26.900 & 26.900 & 26.900 & 26.900 & 26.900 & 26.900 & 26.900 \\
\hline Wheat Pollard & 6.375 & 6.365 & 6.275 & 6.175 & 6.075 & 5.975 & 5.875 \\
\hline Crude palm oil & 3.200 & 3.200 & 3.200 & 3.200 & 3.200 & 3.200 & 3.200 \\
\hline Fish Meal 55\% & 5.000 & 5.000 & 5.000 & 5.000 & 5.000 & 5.000 & 5.000 \\
\hline L-Lysine & 0.250 & 0.250 & 0.250 & 0.250 & 0.250 & 0.250 & 0.250 \\
\hline DL-Methionine & 0.200 & 0.200 & 0.200 & 0.200 & 0.200 & 0.200 & 0.200 \\
\hline $\begin{array}{l}\text { Monodicalcium- } \\
\text { phosphate } 21\end{array}$ & 1.400 & 1.400 & 1.400 & 1.400 & 1.400 & 1.400 & 1.400 \\
\hline Calcium carbonate & 0.992 & 0.992 & 0.992 & 0.992 & 0.992 & 0.992 & 0.992 \\
\hline Choline chloride & 0.058 & 0.058 & 0.058 & 0.058 & 0.058 & 0.058 & 0.058 \\
\hline Salt & 0.250 & 0.250 & 0.250 & 0.250 & 0.250 & 0.250 & 0.250 \\
\hline Mineral Mix² & 0.100 & 0.100 & 0.100 & 0.100 & 0.100 & 0.100 & 0.100 \\
\hline Vitamin $\mathrm{Mix}^{3}$ & 0.058 & 0.058 & 0.058 & 0.058 & 0.058 & 0.058 & 0.058 \\
\hline Antioxidant & 0.008 & 0.008 & 0.008 & 0.008 & 0.008 & 0.008 & 0.008 \\
\hline Alumino silicates & 0.150 & 0.150 & 0.150 & 0.150 & 0.150 & 0.150 & 0.150 \\
\hline Antibiotic $^{4}$ & & 0.010 & & & & & \\
\hline Metabolite powder & & & 0.100 & 0.200 & 0.300 & 0.400 & 0.500 \\
\hline Total & 100 & 100 & 100 & 100 & 100 & 100 & 100 \\
\hline \multicolumn{8}{|l|}{ Calculated analysis: } \\
\hline Crude protein, \% & 20.34 & 20.34 & 20.34 & 20.31 & 20.29 & 20.28 & 20.26 \\
\hline $\mathrm{ME}, \mathrm{kCal} / \mathrm{kg}$ & 2912.30 & 2912.20 & 2912.20 & 2909.76 & 2908.60 & 2907.4 & 2906.16 \\
\hline
\end{tabular}

${ }^{1}$ Diets supplemented with different dosages $(0.1-0.5 \%$, w/w) of metabolite powder of Com3456 (a combination of 4 strains RS5, RI11 RG11 and RG14).

2 Provided per kg diet: Fe 100 mg; Mn 110 mg; Cu 20 mg; Zn 100 mg; I 2 mg; Se 0.2 mg; Co 0.6 mg.

${ }^{3}$ Provided per kg diet: Vitamin A 6,667 IU; vitamin D 1,000 IU; vitamin E 23 IU; vitamin K3 1.33 mg; cobalamin 0.03 mg; Thiamin 0.83 mg; riboflavin 2 mg; folic acid $0.33 \mathrm{mg}$; biotin $0.03 \mathrm{mg}$; pantothenic acid $3.75 \mathrm{mg}$; niacin $23.3 \mathrm{mg}$; pyridoxine $1.33 \mathrm{mg}$.

${ }^{4}$ a combination of oxytetracyclin and neomycin at the concentration of $100 \mathrm{ppm}(\mathrm{w} / \mathrm{w})$

capped vial (Kimble Glass inc., USA) and then dried under a stream of purified nitrogen gas to flush the samples. The cap was then sealed and samples were kept frozen at $-20^{\circ} \mathrm{C}$ until gas chromatography (GC) analysis. Prior to GLC analysis, $1 \mathrm{~mL}$ of chloroformmethanol 2:1 (v/v) mixture was added into the vial containing the cholesterol extract to reconstitute the cholesterol methyl ester.

Cholesterol methyl ester was separated by using an Agilent (Agilent Technologies, Inc., USA) fused silica capillary column $(30 \mathrm{~m}, 0.32 \mathrm{~mm}$ ID, $0.25 \mu \mathrm{m}$ film thickness) in a Hewlett-Packard Model 6890N Gas Chromatograph. The carrier gas was high purity nitrogen at $33.5 \mathrm{~mL} / \mathrm{min}$. High purity hydrogen and compressed air were used in the flame ionization detector of the gas-liquid chromatograph. Oven temperature was set at $310^{\circ} \mathrm{C}$. The set temperature for the injector and detector was $325^{\circ} \mathrm{C}$. Peak area, which reflects the cholesterol content, was determined using a HP-3993A Integrator (Hewlett-Packard, Avondale, PA). Microsoft Excel 2000 (Microsoft Corp., Redmond, USA) was used to express the peak areas as absolute amount of detected cholesterol. Quantification of the cholesterol concentration was based on a standard cholesterol curve at $2 ; 4 ; 6 ; 8$ and $10 \mathrm{mg} / \mathrm{mL}$.

\section{Lactic Acid Bacteria Population in Small Intestine Digesta}

The digesta $L A B$ population was determined using the method described by Foo et al. (2003b). Ten percent $(\mathrm{w} / \mathrm{v})$ of digesta sample was diluted in sterile peptone 
Table 3 - Plasma and meat cholesterol in weeks 3 and 6 of broilers fed diets supplemented with different dosages of Com3456 metabolites.

\begin{tabular}{|c|c|c|c|c|c|c|c|}
\hline \multirow{2}{*}{ Cholesterol, mg/dL } & \multicolumn{7}{|c|}{ Dietary treatments ${ }^{1}$} \\
\hline & -ve control & +ve control & $\begin{array}{c}0.1 \% \\
\text { Com3456 } \\
\end{array}$ & $\begin{array}{c}0.2 \% \\
\text { Com3456 } \\
\end{array}$ & $\begin{array}{c}0.3 \% \\
\text { Com3456 } \\
\end{array}$ & $\begin{array}{c}0.4 \% \\
\text { Com3456 } \\
\end{array}$ & $\begin{array}{c}0.5 \% \\
\text { Com3456 } \\
\end{array}$ \\
\hline \multicolumn{8}{|l|}{ Plasma, mg/dL } \\
\hline Week 3 & $111.08 \pm 4.57^{\text {ba }}$ & $103.27 \pm 2.19^{b}$ & $109.33 \pm 5.99^{\text {ba }}$ & $109.99 \pm 1.25^{\text {ba }}$ & $115.37 \pm 2.74^{\mathrm{a}}$ & $109.56 \pm 2.14^{\text {ba }}$ & $110.51 \pm 0.91^{\text {ba }}$ \\
\hline Week 6 & $149.85 \pm 4.78^{a}$ & $119.18 \pm 5.92^{\mathrm{bc}}$ & $128.80 \pm 3.83^{b}$ & $109.82 \pm 7.4^{c}$ & $108.60 \pm 5.02^{c}$ & $106.23 \pm 4.30^{c}$ & $106.70 \pm 4.14^{c}$ \\
\hline \multicolumn{8}{|l|}{ Meat, mg/100g } \\
\hline Week 3 & $47.54 \pm 3.51^{a}$ & $46.65 \pm 2.66^{a}$ & $43.13 \pm 2.44^{a}$ & $47.82 \pm 3.33^{\mathrm{a}}$ & $44.34 \pm 2.44^{\mathrm{a}}$ & $47.56 \pm 3.96^{a}$ & $45.97 \pm 2.43^{\mathrm{a}}$ \\
\hline Week 6 & $41.40 \pm 1.39^{a}$ & $39.37 \pm 1.26^{\text {bac }}$ & $40.88 \pm 2.24^{\text {ba }}$ & $38.51 \pm 1.04^{\text {bac }}$ & $37.40 \pm 0.87^{b c}$ & $37.52 \pm 0.52^{b c}$ & $36.89 \pm 0.56^{c}$ \\
\hline
\end{tabular}

a-c Row means \pm SEM with different superscript are significantly different $(p<0.05)$.

${ }^{1}$ Diets supplemented with different dosages $(0.1-0.5 \%$, w/w) of metabolite powder of Com3456 (a combination of 4 strains RS5, RI11 RG11 and RG14).

water, left at room temperature for an hour prior to further ten-fold serial dilutions $(\mathrm{v} / \mathrm{V})$. Enumerations of LAB were performed on MRS-agar (LactobacillusAgar De Man, ROGOSA and SHAPE) (Merck®, KgaA, Darmstadt). The plates were incubated in anaerobic jars at $30^{\circ} \mathrm{C}$ for 48 hours. The number of colony-forming units (CFU) was expressed as the base 10 logarithm of CFU (logCFU) per gram. All samples were repeated in triplicate.

\section{Deconjugation of Bile Salts by Lactic Acid Bacteria}

Ten $\mathrm{mL}$ of MRS broth was added to $100 \mu \mathrm{L}$ of each of the 4 substrates $0.2 \mathrm{~g} / \mathrm{mL}$ (sodium glycocholate, sodium taurocholate, sodium glycodeoxycholate and sodium taurodeoxycholate). LAB colonies were isolated on MRS-agar plate and inoculated at $1 \%$ in MRS broth (OD adjusted at 600 nm) and anaerobically incubated at $37^{\circ} \mathrm{C}$ for $24 \mathrm{~h}$. Bile salt deconjugation was determined based on the release of deconjugated bile acids as described by Liong and Shah (2005). Ten mL of culture after the incubation period was adjusted to $\mathrm{pH} 7.0$ with $\mathrm{NaOH}(1 \mathrm{~N})$ and brought up to 12.5 $\mathrm{mL}$ with sterile distilled water. The $L A B$ culture was then centrifuged at $10,000 \mathrm{rpm}$ at $4^{\circ} \mathrm{C}$ for $10 \mathrm{~min}$. Supernatant obtained $(7.5 \mathrm{~mL})$ was adjusted to $\mathrm{pH} 1.0$ with $\mathrm{HCl}(5 \mathrm{~N})$. Two $\mathrm{mL}$ of ethyl acetate were added to $1 \mathrm{~mL}$ of the supernatant and the mixture was vortexed for $1 \mathrm{~min}$. The ethyl acetate layer was transferred to a glass tube and evaporated under nitrogen gas at $60^{\circ} \mathrm{C}$. The residue was immediately dissolved in $0.5 \mathrm{~mL}$ of $0.01 \mathrm{M} \mathrm{NaOH}$ and then $0.5 \mathrm{~mL}$ of furfuraldehyde (1\%) and $0.5 \mathrm{~mL}$ of $8 \mathrm{M} \mathrm{H}_{2} \mathrm{SO}_{4}$ was added. The mixture was then vortexed for $1 \mathrm{~min}$ before heating at $65^{\circ} \mathrm{C}$ in a water bath for $13 \mathrm{~min}$. After cooling, $0.5 \mathrm{~mL}$ of glacial acetic acid was added and the mixture was vortexed for $1 \mathrm{~min}$. The absorbance was read at 660 nm (Pharmacia Novaspec II, Cambridge, England). The amount of deconjugated bile acid released was determined using deconjugated bile acid standard (Sigma Chemical Co., St. Louis, MO, USA). All tested samples were conducted in triplicate.

\section{Data Analysis}

Data were analyzed as a complete randomized design using the General Linear Models procedure of the Statistical Analysis System (SAS, 1998). Duncan Multiple Range Test was used to compare treatment means. Data are presented as the mean \pm standard error of the mean (SEM).

\section{RESULTS}

\section{Plasma and Breast Meat Cholesterol}

Plasma and breast meat cholesterol of chickens in weeks 3 and 6 are shown in Table 3. Plasma cholesterol level of broiler chickens in week 3 was not significantly different $(p>0.05)$ among the treatment groups, except for the significant difference between +ve control and group fed $0.3 \%$ Com3456. The pattern of plasma cholesterol level in week 6 was different from that of week 3 . The highest $(p<0.05)$ level was found in broiler chickens fed the -ve control diet and the lowest $(p<0.05)$ in broiler chickens fed $0.4 \%$ Com3456. Furthermore, plasma cholesterol of -ve control broiler chickens was significantly higher $(p<$ 0.05) than that of the remaining of the treatments.

For the breast meat cholesterol concentration, no significant difference $(p>0.05)$ was found among the 
treatment groups when broilers were 3 weeks of age. However, the trend of breast meat cholesterol level at week 6 was different from that of week 3 . The highest ( $p<0.05$ ) breast meat cholesterol was observed in broiler chickens fed the -ve control diet, followed by group supplemented with $0.1 \%$ Com3456, while no significant difference $(p>0.05)$ was found for the remaining treatments.

\section{Very Low-Density Lipoprotein Profiles}

The VLDL lipid profiles of control groups and treatments supplemented with different concentrations of Com3456 is presented in Table 4. The highest $(p<0.05) F C$ and TG levels were found in the -ve control and the treatment supplemented with $0.4 \%$ Com3456. In contrast, the lowest $(p<0.05)$ FC and TG levels were observed in +ve control and treatment supplemented with $0.3 \%$ Com3456. The other treatment groups presented similar $(p<0.05)$ FC and TG levels. With regard to PL level, the lowest ( $p$ $<0.05$ ) result was found in the +ve control group and that fed $0.3 \%$ Com3456. The other treatments were no significantly different $(p>0.05)$. The CE level was the highest $(p<0.05)$ in -ve control broiler chickens, followed by those fed $0.1 \%$ and $0.4 \%$ Com3456. In contrast, the +ve controls had the lowest $(p<0.05)$ CE concentration. The -ve controls had the highest ( $p$ $<0.05)$ protein concentration among the treatment groups, except for the $0.1 \%$ Com3456 group.
With regard to the surface and core lipids ratios of VLDL particles, diets supplemented with different concentrations of Com3456 had no effect ( $p>0.05$ ) on the surface lipid (PL/FC) ratio. However, the highest $(p<0.05)$ core lipid ratio (TG/CE) was observed in the treatment supplemented with $0.5 \%$, followed by treatment supplemented with $0.4 \%$ Com3456. A similar ( $p>0.05)$ result was found for the remaining treatments. The ratio of the total surface to core lipid components $[(\mathrm{PL}+\mathrm{FC}) /(\mathrm{TG}+\mathrm{CE})]$ of $0.5 \%$ Com3456 was also the highest $(p<0.05)$. However, this ratio was similar $(p>0.05)$ in other treatment groups .

\section{Lactic Acid Bacteria Count and Deconju- gated Bile Acids}

The LAB count in digesta from all the segments of small intestine and quantity of deconjugated bile acid released by deconjugation of different substrates of bile acids by $L A B$ is presented in Table 5 . The highest ( $p<0.05$ ) LAB count was found in the treatment supplemented with $0.5 \%$ Com3456, whereas the -ve control presented the lowest count $(p<0.05)$. The $L A B$ count in the treatment supplemented with $0.1 \%$ Com3456 was not different ( $p>0.05$ ) from that of -ve control. In contrast, LAB count in all other treatments was significantly higher $(p<0.05)$ than the -ve control. The deconjugated bile acids from taurodeoxycholate and glycodeoxycholate substrates were similar $(p>$ 0.05 ) among the treatment groups. However, higher ( $p$

Table 4 - Very low-density lipoprotein lipid profiles of treatments supplemented with different dosages of metabolites from Com3456

\begin{tabular}{|c|c|c|c|c|c|c|c|}
\hline \multirow[b]{2}{*}{ Parameters ${ }^{2}, \mathrm{mg} / \mathrm{mL}$} & \multicolumn{7}{|c|}{ Dietary treatments ${ }^{1}$} \\
\hline & $\begin{array}{c}\text {-ve } \\
\text { control }\end{array}$ & $\begin{array}{c}+\mathrm{ve} \\
\text { control }\end{array}$ & $\begin{array}{c}\text { Com3456 } \\
0.10 \%\end{array}$ & $\begin{array}{c}\text { Com3456 } \\
0.20 \%\end{array}$ & $\begin{array}{c}\text { Com3456 } \\
0.30 \%\end{array}$ & $\begin{array}{c}\text { Com3456 } \\
0.40 \%\end{array}$ & $\begin{array}{c}\text { Com3456 } \\
0.50 \%\end{array}$ \\
\hline FC & $0.28 \pm 0.03^{\text {ba }}$ & $0.16 \pm 0.01^{c}$ & $0.27 \pm 0.04^{\text {ba }}$ & $0.23 \pm 0.01^{b}$ & $0.20 \pm 0.03^{b c}$ & $0.32 \pm 0.03^{a}$ & $0.25 \pm 0.02^{\mathrm{ba}}$ \\
\hline TG & $1.92 \pm 0.24^{\text {ba }}$ & $0.96 \pm 0.14^{c}$ & $1.55 \pm 0.25^{\text {ba }}$ & $1.41 \pm 0.04^{\mathrm{bc}}$ & $0.97 \pm 0.11^{c}$ & $1.94 \pm 0.14^{\mathrm{a}}$ & $1.66 \pm 0.19^{\text {ba }}$ \\
\hline PL & $0.67 \pm 0.08^{\mathrm{a}}$ & $0.32 \pm 0.04^{c}$ & $0.62 \pm 0.10^{\mathrm{a}}$ & $0.51 \pm 0.01^{\text {ba }}$ & $0.40 \pm 0.05^{b c}$ & $0.68 \pm 0.04^{\mathrm{a}}$ & $0.56 \pm 0.06^{\text {ba }}$ \\
\hline CE & $1.11 \pm 0.12^{\mathrm{a}}$ & $0.57 \pm 0.05^{d}$ & $0.99 \pm 0.14^{\text {ba }}$ & $0.81 \pm 0.03^{\mathrm{bdc}}$ & $0.71 \pm 0.08^{d c}$ & $0.94 \pm 0.05^{\text {bac }}$ & $0.83 \pm 0.10^{\text {bdc }}$ \\
\hline Protein & $0.48 \pm 0.05^{\mathrm{a}}$ & $0.26 \pm 0.04^{b}$ & $0.49 \pm 0.11^{\mathrm{a}}$ & $0.28 \pm 0.03^{b}$ & $0.25 \pm 0.05^{b}$ & $0.18 \pm 0.04^{b}$ & $0.25 \pm 0.03^{b}$ \\
\hline PL/FC & $2.33 \pm 0.22^{\mathrm{a}}$ & $1.98 \pm 0.14^{\mathrm{a}}$ & $2.10 \pm 0.14^{\mathrm{a}}$ & $2.26 \pm 0.19^{\mathrm{a}}$ & $1.92 \pm 0.20^{\mathrm{a}}$ & $2.10 \pm 0.06^{\mathrm{a}}$ & $2.43 \pm 0.24^{\mathrm{a}}$ \\
\hline $\mathrm{TG} / \mathrm{CE}$ & $2.92 \pm 0.41^{\mathrm{cb}}$ & $2.70 \pm 0.15^{c}$ & $2.40 \pm 0.14^{c}$ & $3.01 \pm 0.31^{\mathrm{cb}}$ & $2.36 \pm 0.18^{c}$ & $3.87 \pm 0.35^{b}$ & $6.18 \pm 0.51^{\mathrm{a}}$ \\
\hline$(\mathrm{PL}+\mathrm{FC}) /(\mathrm{TG}+\mathrm{CE})$ & $0.39 \pm 0.04^{b}$ & $0.38 \pm 0.02^{b}$ & $0.42 \pm 0.01^{b}$ & $0.40 \pm 0.01^{b}$ & $0.44 \pm 0.04^{b}$ & $0.41 \pm 0.02^{b}$ & $0.65 \pm 0.05^{\mathrm{a}}$ \\
\hline
\end{tabular}

a-dMeans \pm SEM in the same row with common superscript are non-significantly different.

1Diets supplemented with different dosages $(0.1-0.5 \%$, w/w) of metabolite powder of Com3456 (a combination of 4 strains RS5, RI11 RG11 and RG14).

2FC, free cholesterol; TG, triacylglycerol; PL, phospholipid and CE, cholesteryl ester. 
Table 5 - The LAB count in digesta of small intestine and quantity $(\mathrm{mM})$ of deconjugated bile acid released by deconjugation of $L A B$ of broilers fed diets supplemented with different dosages of Com3456 metabolites.

\begin{tabular}{|c|c|c|c|c|c|c|c|}
\hline & \multicolumn{7}{|c|}{ Dietary treatment ${ }^{1}$} \\
\hline & $\begin{array}{l}\text {-ve } \\
\text { control }\end{array}$ & $\begin{array}{l}\text { +ve } \\
\text { control }\end{array}$ & $\begin{array}{c}\text { Com3456 } \\
0.10 \%\end{array}$ & $\begin{array}{c}\text { Com3456 } \\
0.20 \%\end{array}$ & $\begin{array}{c}\text { Com3456 } \\
0.30 \%\end{array}$ & $\begin{array}{c}\text { Com3456 } \\
0.40 \%\end{array}$ & $\begin{array}{c}\text { Com3456 } \\
0.50 \%\end{array}$ \\
\hline LAB, logCFU/g & $3.98 \pm 0.18^{c}$ & $4.31 \pm 0.05^{\text {ba }}$ & $4.08 \pm 0.06^{b c}$ & $4.37 \pm 0.06^{a}$ & $4.57 \pm 0.08^{a}$ & $4.54 \pm 0.08^{a}$ & $4.59 \pm 0.05^{\mathrm{a}}$ \\
\hline
\end{tabular}

Deconjugated bile

acids, $m M$ :

\begin{tabular}{llllllll} 
Taurodeoxycholate & $0.31 \pm 0.06^{\mathrm{a}}$ & $0.28 \pm 004^{\mathrm{a}}$ & $0.28 \pm 0.02^{\mathrm{a}}$ & $0.30 \pm 0.02^{\mathrm{a}}$ & $0.28 \pm 0.03^{\mathrm{a}}$ & $0.31 \pm 0.04^{\mathrm{a}}$ & $0.27 \pm 0,04^{\mathrm{a}}$ \\
\hline Taurocholate & $0.23 \pm 0.04^{\mathrm{c}}$ & $0.35 \pm 006^{\mathrm{bc}}$ & $0.30 \pm 0.07^{\mathrm{bc}}$ & $0.30 \pm 0.02^{\mathrm{bc}}$ & $0.34 \pm 0.03^{\mathrm{bc}}$ & $0.41 \pm 0.05^{\mathrm{ba}}$ & $0.49 \pm 0,05^{\mathrm{a}}$ \\
\hline Glycocholate & $0.20 \pm 0.04^{\mathrm{b}}$ & $0.35 \pm 0.06^{\mathrm{a}}$ & $0.29 \pm 0.04^{\mathrm{ba}}$ & $0.39 \pm 0.03^{\mathrm{a}}$ & $0.34 \pm 0.02^{\mathrm{a}}$ & $0.35 \pm 0.04^{\mathrm{a}}$ & $0.33 \pm 0,04^{\mathrm{a}}$ \\
\hline Glycodeoxycholate & $0.33 \pm 0.04^{\mathrm{a}}$ & $0.27 \pm 0.04^{\mathrm{a}}$ & $0.31 \pm 0.04^{\mathrm{a}}$ & $0.27 \pm 0.02^{\mathrm{a}}$ & $0.27 \pm 0.03^{\mathrm{a}}$ & $0.23 \pm 0.03^{\mathrm{a}}$ & $0.28 \pm 0,04^{\mathrm{a}}$ \\
\hline
\end{tabular}

a-cMeans \pm SEM in the same row with common superscript are non-significantly different.

'Diets supplemented with different dosages $(0.1-0.5 \%$, w/w) of metabolite powder of Com3456 (a combination of 4 strains RS5, RI11 RG11 and RG14).

$<0.05)$ deconjugated bile acid from taurocholate was observed in treatments supplemented with 0.4 and $0.5 \%$ Com3456. Similar results ( $p>0.05)$ were found for the rest of the treatments. With regard to glycocholate, except for the $0.1 \%$ Com3456 group, all other treated groups and +ve control presented significantly higher level $(p<0.05)$ than that of the -ve control.

\section{Relationship of Plasma and Breast Meat Cholesterol and Faecal Microflora Count}

Table 6 shows the Pearson correlation coefficient and significance level between cholesterol and bacterial count. Plasma cholesterol was positively correlated $(p<0.05)$ with breast meat cholesterol in week $6(r=$ $0.54)$. A negative correlation $(r=-0.58, p<0.05)$ was found between LAB count and plasma cholesterol in week 6 . A negative correlation was also observed between $L A B$ and breast meat cholesterol $(r=-0.32$, $\mathrm{p}=0.056)$.

Table 6 - Pearson's correlation coefficients $(r)$ and $p$-value of cholesterol and lactic acid bacteria count at 6 weeks of age

\begin{tabular}{lccc}
\hline $\begin{array}{l}\text { Parameters, } \\
\text { p-value }\end{array}$ & $\begin{array}{c}\text { Plasma } \\
\text { cholesterol }\end{array}$ & Meat cholesterol & LAB \\
\cline { 2 - 4 } $\begin{array}{l}\text { Week 6 } \\
\text { cholesterol }\end{array}$ & 1.000 & Week 6 & Week 6 \\
\hline Meat cholesterol & 0.54 & & \\
& $(0.00)$ & 1.00 & \\
\hline LAB & -0.58 & -0.32 & 1.00 \\
& $(0.00)$ & $(0.05)$ & \\
\hline
\end{tabular}

1 Pearson's correlation coefficient.

${ }^{2}$ value in brackets indicate significance level, $\mathrm{p}$.

${ }^{3} \mathrm{NA}$ : Non-applicable.

\section{DISCUSSION}

\section{Plasma and Breast Meat Cholesterol}

The study showed the cholesterol-lowering effect of the supplementation of Com3456 at different levels. These results are in agreement with the findings of Foo et al. (2003a, b) that Lactobacillus metabolites had positive effects in reducing cholesterol in rats. Anderson \& Gilliland (1999) also reported a reduction of serum cholesterol concentration in humans fed fermented milk containing L. acidophilus L1. Jin et al. (1998) also reported similar cholesterol reduction in broiler chickens fed cultures of Lactobacillus strains. The results was also in agreement with the study of Brashears et al. (1998), who reported a cholesterol removing effect of $L$. casei $N 19$ and E5 and $L$. acidophilus L1 and ATCC 43121 grown in MRS broth at $\mathrm{pH} 6.0$ and without $\mathrm{pH}$ control. The same results of plasma cholesterol reduction were reported by Loh et al. (2003) in rats.

The cholesterol reduction effect can be explained by the increase in microfloral LAB population, leading to a faster rate of cholesterol catabolism by bile acids. Moreover, intestinal LAB can convert primary bile acids into a variety of secondary bile acids by deconjugation ability. This effect causes a decrease of the bile acid level in the intestine. Furthermore, it elevates fecal excretion and accelerates the turnover of bile acids. This leads to a faster rate of cholesterol synthesis for the production of bile acids due to its precursor role of bile acids synthesis (Pereira \& Gibson, 2002). Some strains of Lactobacillus are able to produce exogenous polysaccharides, which can attach to free bile acids 
in the intestine, thus enhancing excretion of the bile acids via the feces (Pigeon et al., 2002). The negative correlation between $L A B$ and cholesterol level also supported the cholesterol lowering effect of $L A B$ in the intestine. In addition to bile salts deconjugation, another way of lowering cholesterol level is the integration of cholesterol into the bacterial cellular membrane (Noh et al., 1997).

\section{Very Low-Density Lipoprotein Profiles}

Besides TG, VLDL particles also contain some cholesteroland cholesterylesters and theapolipoprotein. The availability of cholesterol is required to form the VLDL and transport TG and other lipids (Fungwe et al., 1992). The results of the study showed metabolite supplementation in the diet of broilers reduced CE in VLDL particles compared to the -ve control. This may contribute to the cholesterol reducing effect of metabolite combinations supplementation. As the levels of CE in VLDL particles were lowered, their transportation to extra-hepatic tissues will be lowered as well. This is supported by Fungwe et al. (1992), who reported that the levels of cholesterol and TG are regulated by the secretion and transport of these lipids in the VLDL complex (Fungwe et al., 1992; Loh et al., 2002). Furthermore, CE is the main form of cholesterol in the body (Devlin, 2002). Watanabe et al. (2006) also reported the lowering effects of total plasma cholesterol, TG, LDL, and the increase in HDL in rats fed with traditional fermented food GABA-Tempeh.

It is of particular interest that the molar ratios of the total surface to core lipid components $(\mathrm{PL}+\mathrm{FC} / \mathrm{TG}+\mathrm{CE})$ remained constant regardless of the supplementation of metabolites. The only significantly higher TG/CE and $(\mathrm{PL}+\mathrm{FC}) /(\mathrm{TG}+\mathrm{CE})$ was observed in broiler chickens supplemented with $0.5 \%$ Com3456. Similar surface and lipid ratio suggested the non-significant difference in VLDL particle size among the treatment groups as the surface-core VLDL lipids ratio reflects the VLDL particle size (Fungwe et al., 1992; Loh et al., 2002). However, the protein concentration in VLDL particles was significantly reduced for the $0.2 \%, 0.3 \%, 0.4 \%$ and $0.5 \%$ Com3456 levels. The concentration of protein in VLDL could be used to indicate the number of VLDL particles in the plasma (Loh et al., 2002). These results, therefore, suggest that the numbers of VLDL particles were reduced in broiler chickens fed with different dosages of Com3456.

The protein concentration in $\mathrm{VLDL}$, reflected the number of VLDL particles (Loh et al., 2002). This may be attributed to the mechanisms involved in the metabolism of TG-rich lipoproteins in the plasma as VLDL particles are important in influencing the distribution of TG in plasma to individual tissues and to different fat depots (Griffin and Hermier, 1988). The additional interesting result was the positive correlation ( $r=0.34 ; p=0.03$ ) between CE and plasma cholesterol concentrations. This may be due to that cholesterol is existed mainly in the form of CE (Devlin, 2002).

\section{Lactic Acid Bacteria Count and Bile Salts Deconjugation}

The supplementation of metabolite combinations $(>0.20 \%)$ in the diet of broiler increased the LAB count as compared with the -ve control, which had higher deconjugation ability. Most of treatments supplemented with different dosages of metabolite combinations increased $L A B$ counts in small intestine digesta. The $L A B$ from treatments supplemented with metabolite combinations had higher deconjugation ability, especially taurocholate and glycocholate. The results of deconjugation ability of $L A B$ are in agreement with Tannock et al. (1994), who reported that the concentrations of unconjugated bile acids in the small bowels of mice colonized by lactobacilli are higher than those of animals that do not harbor a Lactobacillus population. Ahn et al. (2003) also reported the higher deconjugation activity of $L$. acidophilus. Deconjugated bile salts are the primary form of removal of cholesterol from the body by excretion (Voet \& Voet, 1995). Most conjugated bile salts are recirculated through the enterohepatic circulation. The bile salts that are excreted must be replaced by new bile acids, which are formed from cholesterol in the body. The more excretion of bile salts, the more cholesterol is being utilized from the pool within the body. Thus, the plasma and breast meat cholesterol concentrations were lower in those broiler chickens supplemented with Com3456 than the -ve control chickens. The bile salts deconjugation ability of LAB was also proven by Chikai et al. (1987), who reported bile salt deconjugation by Bacillus longum increased bile salt excretion in rats. The deconjugation ability of $L A B$ is mainly attributed to the bile salt hydrolase activity. Bile salt deconjugation and bile salt hydrolase activity of 5 bifidobacterial strains and their cholesterol co-precipitating properties were reported by Liong \& Shah (2005).

\section{CONCLUSIONS}

Supplementation of Lactobacillus plantarum metabolite in broiler chicken diets contribute for the reduction of cholesterol concentration in the plasma and breast meat. The mechanisms involved include 
the reduction of CE and number of VLDL particles, as indicated by the VLDL-protein concentration, as well as improved bile salts deconjugation ability by increasing $L A B$ numbers in small intestine digesta.

\section{REFERENCES}

Ahn YT, Kim GB, Lim KS, Baek YJ, Kim HU. Deconjugation of bile salts by L. acidophilus isolates. International Dairy Journal 2003; 13:303-311.

Anderson JW, Gilliland SE. Effect of fermented milk (yogurt) containing L. acidophilus L1 on serum cholesterol in hypercholesterolemic humans. Journal of the American College Nutrition 1999; 18:43-50.

Begley M, Hill C, Gahan CGM. Bile salt hydrolase activity in probiotics. Applied Environmental Microbiology 2006; 72:1729-1738.

Brashears MM, Gilliland SE, Buck M. Bile salt deconjugation and cholesterol removal from media by $L$. casei 1 . Journal of Dairy Science 1998; $81: 2103-2110$

Center SA. Serum bile acid in companion animal medicine. In: Michael SL, editor. Gastroenterology: The 1990l, Philadelphia: SaunderA. 1993. p 625-657.

Chiang JYL. Review: Regulation of bile acid synthesis: pathways, nuclear receptors, and mechanisms. Journal of Hepatology 2004; 40:539-551.

Chikai T, Nakao H, Uchida K.Deconjugation of bile salt acids by human intestinal flora implanted in germ-free rats. Lipids 1987; 22:669-671.

Choe DW, Loh TC, Foo HL, Hair-Bejo M, Awis QS. The egg production performance, faecal $\mathrm{pH}$ and microbial population, small intestinal morphology, plasma and yolk cholesterol in laying hens fed with liquid metabolites produced by Lactobacillus plantarum Strains. British Poultry Science 2012; 1: 106-115

de Almeida JC, Perassolo MS, Camargo JL, Bragagnolo N, Gross JL. Fatty acid composition and cholesterol content of beef and chicken meat in Southern Brazil. Brazilian Journal of Pharmaceutical Sciences 2006; 42:109-117.

Devlin TM. Texbook of Biochemistry with Clinical Correlations. $5^{\text {th }} \mathrm{dn}$. New York: Wiley-LisSA 2002.

Foo HL, Loh TC, Lai PW, Lim YZ, Kufli CN, Rusul G. Effects of adding L. plantarum UL4 metabolites in drinking water of rats. Pakistan. Journal. Nutrition 2003; 2:283-288.

Foo HL, Loh TC, Law FL, Lim YZ, Kufli CN, Rusul G. Effect of feeding L. plantarum UL4 isolated from Malaysian Tempeh on growth performance, faecal flora and lactic acid bacteria and plasma cholesterol concentrations in post-weaning rats. Food Science and Biotechnology 2003; $12: 403-408$

Fungwe TV, Cagen L, Wilcox HG, Heimberg M. Regulation of hepatic secretion of very low-density lipoprotein by dietary cholesterol. Journal of Lipid Research 1992; 33:179-191.

Griffin $H$, Hermier D. Plasma lipoprotein metabolism and fattening in poultry. In: Leclercq, Whitehead CC. Leanness in Domestic Birds. Butterworthnd 1988; p 175 - 201

Jin LZ, Ho YW, Abdulah N, Jalaludin S. Effects of adherent Lactobacillus cultures on growth, weight of organs and intestinal microflora and volatile fatty acids in broilers. Poultry Science 1998; 77:1259-1265.

Liong MT, Shah NP. Bile salt deconjugation and BSH activity of five bifidobacterial strains and their cholesterol co-precipitating properties. Food Research International 2005; 38:135-142.
Loh TC, Thanh NT, Foo HL, Bejo MH, Kasim 0. Feeding of different levels of metabolite combinations produced by Lactobacillus plantarum on growth performance, faecal lactic acid bacteria and Enterobacteriaceae count, volatile fatty acids and villi height in broilers. Animal Science Journal 2010;8, 205-214.

Loh TC, Chong SW, Foo HL, Law 09. Effects on growth performance, faecal microflora and plasma cholesterol after feeding with spraydried metabolite in postweaning rats. Czech Journal of Animal Science 2009 5: $10-16$.

Loh TC, Lee TM, Foo HL, Law FL, Rajion MA. Growth performance and faecal microflora of rats offered with metabolites from lactic acid bacteria in drinking water. Journal of Applied Animal Research 2008; 34:61-64

Loh TC, Foo HL, Tan BK, Jelan ZA. Effects of palm kernel cake on growth performance and blood lipids in rats. Asian-Australasian Journal of Animal Science 2002; 15:1165-1169.

Loh TC, Foo HL Tan SH, Goh YM, Shukriyah MH, Kufli CN. Effects of fermented products on performance, faecal pH, Enterobacteriaceae and lactic acid bacteria counts and relationships, and plasma cholesterol concentration in rats. Journal of Animal and Feed Sciences 2003; 12:633-644.

Noh DO, Kim SH, Gilliland SE. Incorporation of cholesterol into the cellular membrane of $L$. acidophilus ATCC 43121. Journal of Dairy Science $1997 ; 80: 3107-3113$

Pereira DIA, Gibson GR. Cholesterol assimilation by lactic acid bacteria and bifidobacteria isolated from the human gut. Applied Environmental Microbiology 2002; 68:4689-4693.

Pigeon RM, Cuesta EP, Gilliland SE. Binding of free bile acids by cells of yogurt starter culture bacteria. Journal of Dairy Science 2002; 85:27052710

SAS Institute. SASuUser' Gguide. Statistics. Cary: SAS Institut. 1998 C.

Schiff ER, Small NC, Dietschy JM. Characterization of the kinetics of the passive and active transport mechanisms for bile acid absorption in the small intestine and colon of the rat. Journal Clinical Investigation 1972 ; 51:1351-1362.

Tan BK, Foo HL, Loh TC, Norhani A, Zulkifli I. Purification and characterisation of very low density lipoprotein in commercial broiler and crossbred village chickens by fast liquid chromatography. Asian-Australasian Journal of Animal Science 2005; 12:1780-1785.

Tannock GW, Tangerman A, Van Schaik A, McConnell MA. Deconjugation of bile acids by lactobacilli in the mouse small bowel. Applied Environmental Microbiology 1994; 60:3419-3420.

Thanh NT, Loh TC, Foo HL, Bejo, MH, Kasim A. Effects of feeding metabolite combinations produced by Lactobacillus plantarum on growth performance, faecal microbial population, small intestine villus height and faecal volatile fatty acids in broilers. British Poultry Science 2009; 50:298-306.

Thu TV, Foo HL, Loh TC, Bejo MH. Effects of Metabolite Combinations Produced by Lactobacillus plantarum on Plasma Cholesterol and Fatty Acids in Piglets. American Journal of Animal and Veterinary Science 2010; 5: 233-236

Thu, TV, Foo HL, Loh TC Bejo MH Inhibitory activity and organic acids concentrations of metabolite combinations produced by various strains of Lactobacillus plantarum. Africn. Journal of Biotechnology 2011a. 1: 1359-1363.

Thu TV, Loh TC, Foo HL, Halimantun Y, Bejo MH. Effects of liquid metabolites combinations by Lactobacillus plantarum on growth performance, 
faeces characteristics, intestinal morphology and diarrhea incidence in postweaning piglets. Tropical Animal Health and Production 2011b; 4: $69-75$

Voet D, Voet JG. Biochemistry. $2^{\text {nd }} \mathrm{n}$. New York: John Wiley \& Sons. 1995.

Walker DK, Gilliland SE. Relationships among bile tolerance, bile salt deconjugation, and assimilation of cholesterol by L. acidophilus. Journal of Dairy Sciene. 1993; 76:956-961.

Watanabe N, Endo Y, Fujimoto K, Aoki H. Tempeh-like fermented soybean (GABA-tempeh) has an effective influence on lipid metabolism in rats. Journal of Oleo Science 2006; 55:391-396.

Wright MM, Lean IJ, Herrera E, Dodds PF. Changes in the composition of plasma very low density lipoprotein during pregnancy and lactation in genetic lines of pigs. Animal Science Journal 1995; 61:361-365. 